\title{
Modeling the stress complexities of teaching and learning of school physics in Nigeria
}

\author{
Moses E. Emetere \\ Department of Physics, Covenant University, Canaan land, P.M.B 1023, Ota-Nigeria \\ For correspondence: moses.emetere@covenantuniversity.edu.ng
}

\begin{abstract}
This study was designed to investigate the validity of the stress complexity model (SCM) to teaching and learning of school physics in Abuja municipal area council of Abuja, North. About two hundred students were randomly selected by a simple random sampling technique from some schools within the Abuja municipal area council. A survey research design was used which centered on the students perception only. The data collected were analyzed using Pearson product moment correlation, standard deviation and behavioral complexity model. The findings of the study revealed that psychosocial stress emanating from the classrooms in developing country yields higher negative feedbacks than positive feedbacks.
\end{abstract}

Keywords: stress complexity model, school physics, secondary school, mathematical modeling, statistical analysis

\section{Introduction}

Educationist have (Awokoya, 1975; Emetere, 2014) highlighted the need for improving resources (i.e. funds, manpower e.t.c.) in science education. The dynamism of 'science and technology have become an integral part of the world culture, therefore for any nation to be relevant, it must not overlook the importance of science in her educational system'(Fafunwa, 1980). The educational systems in Nigeria had been remodeled severally to drive-in the required potentials for improving the science education. However, not much improvement has been recorded via the national qualifying exams for high schools (ogbongeblog, 2010). More specifically, the learning and teaching of school physics in developing nations have suffered set-back frequently because its challenges are myriads and thus be classified into predictable and unpredictable factors. The predictable factors include the use of digitized teaching aids, preparing reader-friendly e-notes, dissemination of e-notes, dwindling internet connection, interrupting power supply, inadequate distribution of output devices to staff and students e.g. computer, production output of projectors, technical know-how, unorganized physics curriculum, inadequacy of teaching aids, poor infrastructure, unqualified teacher, inadequate apparatus for demonstration classes, misappropriation of funds, students attitude towards learning e.t.c. The unpredictable factors are the learning attitudes, the teaching attitudes, stress, brain development of the learner e.t.c. However, the unpredictable factor determines $80 \%$ of learning and teaching successes. This is the major objective of this research. The estimation of stress to learning can be challenging in developing countries, especially in relation to behavioural studies (Lighthall et al., 2009). Scientist have propounded that stress may enhance learning outcomes. For example, Petzold et al., (2010) proved that psychosocial stressor impaired learning had less effect on positive feedbacks than negative feedback. Unlike the developed countries, the 
psychosocial stress effects are negatively affected by economy inadequacies e.g. hunger and lack. Hence, the stress outcomes in a developing country is prone to be negative than positive feedback. The teacher's psychosocial stresses are emotionally transferable to the learner and it varies from one country to another. For example, the use of mathematics as the only language used for describing and conveying ideas in school physics is still predominant in most developing countries (Maliki et al, 2009). The teachers' inadequacies are easily transferable to the learner by creating a huge psychological barrier to the teaching and learning of school physics. Attitudes are acquired through learning and can be changed through persuasion using variety of techniques. It helps to shape the experiences an individual has with object, subject or person. The stress initiated attitude may established by giving the learner multi task that engenders learners interest. Learner constantly form new attitudes and modify old ones when they are exposed to new information and new experiences (Adesina et al,2005). Therefore, solving stress issues confronting school physics in developing countries can be achieved via propounding stress models. 'A model is not only a substitute of the actual system, it also the simplification of the system' (Dinesh, 2012). A stress model can be any of the following, physical static model, physical dynamic model, mathematical static model, mathematical dynamic model, mathematical static analytical model, mathematical dynamic numerical model e.t.c.

In this paper, we shall be concentrating on the physical dynamic model. This type of model examines behavioural factors/parameters that could change with respect to time. Therefore we shall concentrate on some behavioural parameters like Students' background knowledge, Students' perception of the volume of assignment given by the teacher, relevance of physics to students' future e.t.c.

\section{Statement of Problem}

The poor student performance in the National Examination Council (NECO) and Joint Admission and Matriculation (JAMB) examinations for the past three years has been below thirty percent (ogbongeblog, 2010). Efforts by state and federal government, multi-nationals and social groups to modernize the learning environment of the students have not shown significant improvements on the annuals results. The priorities of teaching school physics in Nigeria (Onah, 2010; Emetere,2014) seem to be misplaced via emphasis on hardwares over attitude development - both to the teacher and the learner.

\section{Research Design}

The design employed for the study was a survey method which entails collection of data from the sampled segment of the society of interest (Fafunwa, 1980). The findings from the sampled segment (i.e. the largest region of Abuja) of the population are used to generalize for the entire population (i.e. Abuja). The questionnaire consist of nine sections all integrated as one- at first glance. Section $\mathbf{A}$ of the questionnaire i.e. questions 1-3, consist of fundamental problems faced by the students' which is largely traceable to their background knowledge. Section B of the questionnaire i.e. question 4-5, consists of the students' performance in physics. Section $\mathbf{C}$ of the questionnaire i.e. question 6 consists of students' perception of the volume of assignment given by their teachers. Section $\mathbf{D}$ of the questionnaire i.e. question 7 consists of students' choice of resource materials. Section $\mathbf{E}$ of the questionnaire i.e. question 8 consists of the relevance of physics to the students future ambition. The questionnaire was drafted to address few learning problems. This research is enforced by Section A,C \& E. 


\section{Sampling Techniques}

The sample of the study was selected using the multi-stage sampling procedure. Two hundred (200) students were selected by using a simple random sampling technique from one (1) public secondary school and two (2) private secondary schools. Simple random sampling technique was used to select the participating students'. The senior secondary school three (SS3) class were majority (50\%), followed by senior secondary school two (SS2) class (35\%). Senior secondary school one (SS1) were the minority (15\%) because they are still at the rudimentary stage of school physics.

\section{Model Formalism}

Let the stress complexities of the students be given as $\beta$ which is assumed to be a polynomial because stress has the tendency to affect positively or negatively. Hence, $\cos ^{-1}\left(\frac{\beta_{x}}{\beta}\right)=\theta$ is the positive stress complexities of the student and $\sin ^{-1}\left(\frac{\beta_{y}}{\beta}\right)=\emptyset$ the negative stress complexities of the students. Here, $\theta$ and $\emptyset$ are the behavioral deviations which is represented. $\beta_{y}=\beta-\beta_{0}$ and $\beta_{x}=f-\frac{\beta_{0}}{\beta} . x=\beta_{0}$ is the class mean.

$$
n=\frac{\sin (\theta)}{\sin (\varnothing)}
$$

$\mathrm{n}$ is the stress refractivity which determines the positivity or negativity during stress analysis. If $n>1$, then the stress supports positive learning, $n<1$ the stress yields negative learning and $n \neq$ numerical value, the stress is unpredictable, $f$ is the frequency.

\section{Results and Discussion}

Table 1: Students' background knowledge

\begin{tabular}{lcc}
\hline & FREQUENCY & PERCENTAGE \\
\hline WEAK & 9 & $9.8 \%$ \\
FAIR & 26 & $28.2 \%$ \\
GOOD & 44 & $47.9 \%$ \\
VERY GOOD & 13 & $14.1 \%$ \\
\hline
\end{tabular}

Table 2: Standard deviation of students' background knowledge

\begin{tabular}{|c|c|c|}
\hline$X$ & $X-x$ & $(X-x)^{2}$ \\
\hline 9 & -14 & 196 \\
\hline 26 & 3 & 9 \\
\hline 44 & 21 & 441 \\
\hline 13 & -10 & 100 \\
\hline$X=92$ & & $(X-x)^{2}=746$ \\
\hline
\end{tabular}

The standard deviation is therefore given as $\quad S . D=\sqrt{\frac{(X-x)^{2}}{N}}=13.1$

A good number of student falls under the fair and poor category. This shows that some of the student had a poor primary or junior secondary school background. The standard deviation of the group of students' under this section is given as 13.1. This value is interpreted as dangerous (Dusaro, 2004) to the learning of physics in the schools.

We applied the stress complexity model (SCM) to generate data set shown in Table 3 
Table 3: Hypothesis via stress complexity model (SCM)

\begin{tabular}{lcccccc}
\hline & FREQUENCY & $\beta_{x}$ & $\beta_{y}$ & $\theta(\circ)$ & $\emptyset(\circ)$ & $\mathrm{n}$ \\
\hline WEAK & 9 & 8.75 & -14 & 84.5 & -8.8 & -6.5 \\
FAIR & 26 & 25.75 & 3 & 73.5 & 1.9 & $\mathbf{2 8 . 9}$ \\
GOOD & 44 & 43.75 & 21 & 61.6 & 13.2 & 3.8 \\
VERY GOOD & 13 & 12.75 & -10 & 82.0 & -6.2 & -9.2 \\
\hline
\end{tabular}

Since the negative has the highest value of stress refractivity. This shows that the stress in the class inhibits performance. We affirm our guess by looking at the students' performance (as shown in Tables 4 \&5) .

Table 4: Students' performance in physics

\begin{tabular}{lll}
\hline & FREQUENCY & PERCENTAGE \\
\hline POOR & 16 & $18.3 \%$ \\
AVERAGE & 33 & $37.5 \%$ \\
GOOD & 27 & $30.7 \%$ \\
VERY GOOD & 11 & $12.5 \%$ \\
\hline
\end{tabular}

Table 5: Standard deviation of students' performance

\begin{tabular}{|c|c|c|}
\hline $\mathrm{X}$ & $\mathrm{X}-\mathrm{x}$ & $(\mathrm{X}-\mathrm{x})^{2}$ \\
\hline 16 & -5.75 & 33.06 \\
\hline 33 & 11.25 & 126.56 \\
\hline 27 & 5.25 & 27.56 \\
\hline 11 & -10.75 & 115.56 \\
\hline
\end{tabular}

Table 6: Analysis of students' background knowledge and students' performance using the Pearson product moment correlation

\begin{tabular}{llllll}
\hline $\mathbf{N}$ & $\mathbf{X}$ & $\mathbf{Y}$ & $\mathbf{X}^{2}$ & $\mathbf{Y}^{2}$ & $\mathbf{X Y}$ \\
\hline $\mathbf{1}$ & 16 & 9 & 256 & 81 & 144 \\
$\mathbf{2}$ & 33 & 26 & 1089 & 676 & 858 \\
$\mathbf{3}$ & 27 & 44 & 729 & 1936 & 1188 \\
$\mathbf{4}$ & 11 & 13 & 121 & 169 & 143 \\
$\mathbf{5}$ & $\mathbf{X}=87$ & $\mathrm{Y}=92$ & $\mathrm{X}^{2}=2195$ & $\mathrm{Y}^{2}=2862$ & $\mathrm{XY}=2333$ \\
\hline
\end{tabular}

The standard deviation is therefore given as $\quad S . D=\sqrt{\frac{(X-x)^{2}}{N}}=8.7$. We further compared the students knowledge to their performance (as shown in Table 6 below)

$$
\begin{gathered}
r=\frac{N\left(\sum X Y\right)-\left(\sum X\right)\left(\sum Y\right)}{\sqrt{N\left(\sum X^{2}\right)-\left(\sum X\right)^{2}\left[N\left(\sum Y^{2}\right)-\left(\sum Y\right)^{2}\right]}} \\
r=\frac{1328}{\sqrt{(1211)(2984)}} \\
r=0.70
\end{gathered}
$$

It was discovered that the students' background knowledge and their performance in physics are directly related. This validates the stress complexity model (SCM). Also, the students' perception of the volume of 
assignment given by the teacher and the relevance of physics to students' future was investigated corroborate the prediction of the stress complexity model (SCM).

Table 7: Students' perception of the volume of assignment given by the teacher

\begin{tabular}{lll}
\hline & FREQUENCY & PERCENTAGE \\
\hline OKAY & 13 & $15.5 \%$ \\
FEW & 4 & $4.8 \%$ \\
TOO MUCH & 67 & $79.7 \%$ \\
\hline
\end{tabular}

Table 7 shows the negativity of stress to learning in developing country. This stress outcome result may be connected to inadequate of funds or textbooks, negative experiences formed via unproductive stress management, limited time for lesson delivery e.t.c.

Table 8: Relevance of physics to students' future

\begin{tabular}{llc}
\hline & FREQUENCY & PERCENTAGE \\
\hline YES & 58 & $70.7 \%$ \\
NO & 24 & $29.3 \%$ \\
\hline
\end{tabular}

Table 9: Resource material used by students'

\begin{tabular}{lcc}
\hline & FREQUENCY & PERCENTAGE \\
\hline NO ANSWER & 8 & $11.0 \%$ \\
POOR PICTURE & 1 & $1.3 \%$ \\
NOTHING & 10 & $13.7 \%$ \\
TOO MUCH EXPLANATION & 28 & $38.4 \%$ \\
DON'T UNDERSTAND & 14 & $19.1 \%$ \\
NOT COMPREHENSIVE & 8 & $11.0 \%$ \\
VOCABULARY & 4 & $5.5 \%$ \\
\hline
\end{tabular}

Tables $8 \& 9$, shows some of the causes of negative impact of stress to learning. While Table 8 shows the population of distraction in the class, Table 8 shows the problem students encounter when studying the textbooks. This is a clue for authors to make their textbook users-friendly i.e. having colorful diagrams. The data shows that while some students actually read their textbooks with the aim of doing their assignments. For example $38 \%$ of the students say there are too many facts in the textbooks, $6 \%$ says the vocabularies were complex, $19 \%$ says they don't understand the textbook. This problem may be the problem of presentation of facts by authors or the use of grammar which may be confusing to the reader. Educationists have highlighted ways of curbing stress in developing country like Nigeria (Emetere, 2006). One of the solutions was organizing a productive career workshop both for teachers and learner, restructuring the curriculum to include more audio-visuals e.t.c.

\section{Conclusion}

The stress complexity model (SCM) has been validated via additional parameters. Therefore, stress complexities in most part of developing countries can be obtained without rigorous and outdated evaluation techniques. Teachers may find SCM useful because it determines the authentic type of stress outcomes of a class within a specific time. Therefore, the SCM can be used by teachers and school administrator to monitor student's attitude towards learning school physics. The model could also be use to ascertain the teachers class control. Lastly, the enhancement of positive feedbacks via psychosocial 
stress can be achieved by adopting - more of interactive audio-visuals, reader-friendly textbook of few pages, emphasis of any lesson should driven via psychomotor. Further work is expected to computerize the model to make it less cumbersome for users.

\section{Appreciation}

The author would like to thank Dr.A.I Ugwu and Mrs J. Emetere for their contribution to the writing of this paper. The paper is self sponsored.

\section{Reference}

Awokoya S.O., (1975). Relevant of science teaching to the needs of the communication. Journal of STAN 14(13), pp.57-68

Adesina, A.O. \& Akinbobola, A.O., (2005). The attitude of students' towards part-time degree programme of the faculty of education, Obafemi Awolowo University, Ile-Ife. Journal of Research of Education, 2(1), pp.1-4.

Agnes Ebi Maliki, Anthony Ntol Ngbu and Julie E. Ibu (2009). Analysis of students' performance in junior secondary school mathematics examination in Bayelsa state of Nigeria. Stud Home comm.. sci. 3(2) pp. 131-134.

Dinesh K. S., (2012). International Journal of Applied Physics and Mathematics, 2 (5), 312-315

Emetere, M.E., (2006). Becoming A Scientist, Skaron Prints, Volume 1, pp.35-37 (ISBN 978-071-702-1)

Emetere, M.E., (2014). Modeling the Behavioral Complexities towards the Teaching and Learning of School Physics. Pensee Journal 76 (4), pp. $258-265$

Fafunwa B., (1980) New perpective of African Education London and Basingstone, Macmillan

Lighthall, N. R., Mather, M., \& Gorlick, M. A., (2009). Acute stress increases sex differences in risk seeking in the Balloon Analogue Risk Task. PLoS ONE, 4, e6002.

Onah D.U and Ugwu E.I., (2010). Factors which predict performance in secondary school physics in Ebonyi north educational zone of Ebonyi state, Nigeria. Advances in Applied Science Research 1(3), pp.255-258

Ogbongeblong (2010).m.ogbongeblog.com/2010/09/necoresults-for junejuly-2010

Petzold, A., Plessow, F., Goschke, T., \& Kirschbaum, C., (2010). Stress reduces use of negative feedback in a feedback-based learning task. Behavioral Neuroscience, 124, 248-255. 